\title{
Faktor yang Mempengaruhi Ibu Hamil Memilih Penolong Persalinan di Wilayah Kerja Puskesmas Malakopa Kabupaten Kepulauan Mentawai
}

\author{
Factors Affecting Pregnant Women Choosing Childbirth attendants \\ in the Work Area of Malakopa Health Center Mentawai Islands District
}

Desi Fitrianeti ${ }^{1}$, Lukman Waris ${ }^{1}$, Aris Yulianto ${ }^{1}$

1) Pusat Penelitian dan Pengembangan Sumber Daya dan Pelayanan Kesehatan, Jalan Percetakan Negara No. 29 Jakarta 10560, Indonesia

Korespondensi: desifitrianeti@gmail.com

Submitted: 18 Juli 2018, Revised: 28 November 2018, Accepted: 12 Desember 2018

https://doi.org/10.22435/jpppk.v2i3.126

\begin{abstract}
Abstrak
Kematian ibu dan anak masih menjadi masalah kesehatan. Risiko mengalami kematian ibu atau bayi bagi ibu melahirkan sangat dipengaruhi di mana seorang ibu hamil memilih penolong persalinan. Studi ini bertujuan untuk mengetahui faktor-faktor yang mempengaruhi ibu hamil dalam memilih penolong persalinan di wilayah kerja Puskesmas Malakopa Kabupaten Kepulauan Mentawai. Metode penelitian kuantitatif dengan desain potong lintang. Data dikumpulkan pada Puskesmas Malakopa Kabupaten Kepulauan Mentawai Provinsi Sumatrera Barat bulan Maret 2017. Teknik pengambilan sampel secara random sampling, data dianalisis dengan menggunakan SPSS. Pengumpulan data melalui observasi, wawancara, dan telaah dokumen. Hasil penelitian Ibu hamil di wilayah Puskesmas Malakopa yang memilih bersalin dengan tenaga kesehatan sebesar $62,9 \%$, persalinan ditolong oleh tenaga non kesehatan sebesar $37,1 \%$. Uji statistik menunjukkan tidak terdapat hubungan bermakna antara faktor internal dan eksternal pada kelompok ibu hamil terhadap pemilihan penolong persalinan. Untuk itu disarankan dalam meningkatkan cakupan persalinan nakes di wilayah kerja Puskesmas Malakopa Kabupaten Kepulauan Mentawai diperlukan perhatian kusus bagi tenaga kesehatan terhadap faktor yang mempengaruhi ibu hamil dalam memilih penolong persalinan.
\end{abstract}

Kata kunci: Ibu Hamil, Penolong Persalinan

\begin{abstract}
Maternal and child mortality is still becoming health problem. The risk of having a mother or baby's death for the mother of childbirth is strongly influenced where a pregnant woman chooses a birth attendant. This study aimed to determine the factors that influence pregnant women in choosing birth attendants in the working area of Malakopa Health Center, Mentawai Islands District. This research is quantitative method with cross- sectional design. Data was collected at Malakopa Health Center, Mentawai Islands District, West Sumatera Province, in March 2017. The sampling technique was random sampling. Data was analyzed using SPSS. Collecting data through observation, interviews, and document review. The results of the study of pregnant women in the Malakopa Health Center area who chose to give birth with health workers were $62.9 \%$, deliveries were assisted by non-health workers by $37.1 \%$. The statistic test showed no significant relationship between internal and external factors in the group of pregnant women on the selection of birth attendants. It is recommended that in increasing coverage of health workers in the working area of the Malakopa Health Center, Mentawai District need special attention for health workers on factors that affect pregnant women in choosing birth attendants.
\end{abstract}

Keywords: Pregnant Women, Birth attendants 


\section{Pendahuluan}

Tingginya Angka Kematian Ibu (AKI) dan Angka Kematian Bayi (AKB) di Indonesia masih menjadi permasalahan prioritas utama yang harus segera diselesaikan. Menurut Dewi dalam Yulfira Media 2014, tingginya AKI dan AKB di disebabkan karena masih banyaknya ibu hamil yang tidak melakukan pemeriksaan kehamilan, dan tidak mendapatkan pemeriksaan sesuai standar program ibu dan anak dari tenaga professional karena belum sepenuhnya dimanfaatkan oleh masyarakat.

Menurut Rencana Strategis Kementerian Kesehatan, indikator MDG's tahun 2015, Indonesia berkomitmen untuk menurunkan angka kematian ibu AKI 102/100.000 kelahiran hidup, AKB 23/1000 kelahiran hidup. ${ }^{2}$ Berdasarkan laporan Depkes 2008 setiap tahun sekitar 20.000 perempuan di Indonesia meninggal dunia akibat komplikasi dalam persalinan. Penyebab kematian ibu yang terbanyak (90\%) disebabkan oleh komplikasi obstetri diantaranya pendarahan $40-50 \%$, preeklamsi $15-20 \%$, infeksi $10-15 \%{ }^{3}$ Provinsi yang paling tinggi AKB di Indonesia adalah Jawa Barat, Jawa Tengah, Jawa Timur, Sumatera Utara, Banten, sementara paling tinggi AKI adalah Jawa Barat, Jawa Tengah, Jawa Timur, Sumatera Utara, dan NTT. Untuk penyumbang angka kematian ibu yang paling banyak adalah Jawa Barat, Jawa Tengah, Jawa Timur, Sumatera Utara, dan NTT. ${ }^{4}$ AKI dan AKB adalah salah satu indikator IPM yang berpengaruh dalam menentukan Umur Harapan Hidup (UHH). UHH adalah merupakan indikator pembangunan kesehatan. ${ }^{5}$

Menurut data Survei Dasar Demografi dan Kesehatan Indonesia (SDKI) 2007 menyebutkan bahwa AKI 228 per 100.000 kelahiran hidup. Tahun 2012 berdasarkan Data SDKI menyatakan bahwa ada peningkatan AKI menjadi 359/100.000 kelahiran hidup. Kasus kematian ibu dan anak dapat dicegah jika persalinan ditolong oleh tenaga kesehatan di fasilitas kesehatan. Cakupan persalinan yang ditolong oleh tenaga kesehatan terlatih diharapkan semakin meningkat. Semakin tinggi cakupan persalinan oleh tenaga kesehatan yang terlatih akan diikuti dengan penurunan AKI. ${ }^{6}$ Berdasarkan data Ditjen Bina Gizi dan KIA Kemenkes RI tahun 2013, pertolongan persalinan oleh tenaga kesehatan di Indonesia sebesar 90,88\%. Standar Pelayanan
Minimal (SPM) menentukan indikator cakupan pertolongan persalinan oleh tenaga kesehatan yang memiliki kompetensi kebidanan 90\% tahun 2015. Penyebab medis tersebut diperparah dengan penyebab tidak langsung yang disebut dengan Empat Terlalu (4T) yaitu: perempuan melahirkan terlalu muda atau terlalu tua, terlalu banyak anak dan jarak kelahiran antara anak terlalu dekat. Penyebab lainnya yang memegang peranan penting adalah terlambat yang dikenal dengan istilah 'Tiga Terlambat' (3T) yaitu 1. Terlambat mendiagnosa, 2 . Terlambat merujuk dan 3. Terlambat mendapatkan pertolongan di fasilitas kesehatan. ${ }^{7}$ Peningkatan kasus AKI dan AKB di Indonesia sebagian besar terjadi karena adanya komplikasi obstetri. Kejadian ini tidak selalu dapat diramalkan pada ibu hamil yang telah di identifikasikan normal. ${ }^{8}$

Berdasarkan Permenkes No.97 tahun 2014 tentang pelayanan kesehatan masa sebelum hamil, masa hamil, persalinan, dan masa sesudah melahirkan pada pasal 14 ayat 1 berbunyi persalinan harus dilakukan di fasilitas pelayanan kesehatan. Menurut PP No.61 tahun 2014 pasal 16 nomor 4 menyatakan bahwa Bidan dapat melakukan pelayanan kesehatan jika fasilitas kesehatan sulit dijangkau, karena ada disparitas geografis dan transportasi yang tidak memungkinkan. Menurut Sundoyo (2018), menyatakan bahwa pelayanan kesehatan harus dilakukan sama di seluruh Indonesia, agar kesehatan ibu dapat terjaga dan angka kematian ibu dan anak dapat di turunkan. ${ }^{9}$ Pelayanan Kesehatan yang di maksud adalah pelayanan kesehatan ibu hamil khususnya pelayanan persalinan. Menurut Marisah (2011), menyatakan persalinan adalah proses pengeluaran hasil konsepsi dari rahim ibu melalui jalan lahir atau dengan jalan lain, yang kemudian janin dapat hidup ke dunia luar. Secara alamiah ibu bersalin akan mengeluarkan banyak energi dan mengalami perubahan, baik secara fisiologis maupun psikologis. ${ }^{10}$

Kabupaten Kepulauan Mentawai Provinsi Sumatera Barat masih dihadapkan tingginya AKI dan AKB. Kematian ibu melahirkan masih terjadi 8 kasus tahun 2014 meningkat 9 kasus tahun 2015 dan turun menjadi 6 kasus tahun 2016. Pada tahun 2016 jumlah kasus kematian ibu turun menjadi 6 jiwa. Masih tingginya kasus AKB dan AKI disebabkan karena masih rendahnya ibu hamil melakukan kontak 
dengan tenaga persalinan di fasilitas pelayanan kesehatan hanya sebesar sebesar $26,3 \%$. Puskesmas Malakopa merupakan 1 dari 12 Puskesmas yang ada di wilayah Kabupaten Kepulauan Mentawai. Data sasaran KIA ibu hamil yang bersalin di Puskesmas Malakopa sebesar 42,5\% atau 102 jiwa. Menyebutkan pada tahun yang sama terjadinya kematian ibu (AKI) 2016 sebanyak 2 orang disebabkan karena infeksi (1 kasus), dan emboli (1) kasus. Dan kasus kematian balita sebanyak 2 orang disebabkan karena aspiksia (2 kasus). Sebagai daerah kepulauan (DTPK) masyarakat Kabupaten Kepulauan Mentawai mengalami kesulitan dalam hal akses transportasi ke fasilitas kesehatan, kendala geografis ini dapat menyebabkan keterlambatan penanganan kasus emergency maternal. ${ }^{11}$ Penelitian ini bertujuan untuk mengidentifikasi faktor yang mempengaruhi ibu hamil dalam memilih penolong persalinan di Puskesmas Malakopa Kabupaten Kepulauan Mentawai.

\section{Metode Penelitian}

Penelitian ini bersifat analitis dengan menggunakan metode kuantitatif, dengan desain potong lintang. Populasi adalah seluruh ibu hamil yang bersalin di wilayah kerja Puskesmas Malakopa (rentang periode bulan Januari s/d Desember tahun 2016), berjumlah sebanyak 102 orang. Kriteria inklusi adalah ibu hamil yang bersalin secara normal/dengan penyulit (sunsang/retensio placenta) ditolong dengan tenaga kesehatan/non kesehatan, anak yang dilahirkan hidup di wilayah kerja Puskesmas Malakopa, bersedia diwawancarai dan menandatangani informed consent. Kriteria Eklusi adalah ibu hamil meninggal, dan anak meninggal yang tidak diwawancarai. Teknik pengambilan sampel secara random sampling, besar sampel minimal menurut Taro Yamane dalam Imron Moch (2010) dengan rumus $\left(n=N / \mathrm{Nd}^{2}+1\right)$ sebanyak 51 orang, dan ditambah $10 \%$ sebagai cadangan, total sampel menjadi 56 orang. ${ }^{12}$ Namun pada saat pengumpulan data yang berhasil diwawancarai sebanyak 35 orang karena adanya ibu bersalin sebanyak 6 orang tidak bersedia diwawancarai, 11 orang ibu bersalin tidak ditemukan karena sudah pindah, 2 orang ibu hamil anaknya meninggal karena asfiksia, 1 orang ibu bersalin meninggal dunia karena infeksi, dan 1 orang mati karena emboli.
Data diperoleh melalui observasi, wawancara dan dilakukan telaah dokumen. Data primer dan sekunder diolah dengan melakukan uji eksak fisher untuk melihat hubungan antar variabel independen yang terdiri dari (A) faktor internal ibu meliputi (1) Pendidikan di ukur dengan kriteria rendah bila tamat SMP kebawah, dan tinggi bila tamat SMA keatas. (2) Status pekerjaan di ukur dengan kriteria ibu bekerja dan tidak bekerja. (3) Pengetahuan di ukur dari beberapa pertanyaan terkait bila skor rendah nilai $\leq$ dari 5 dan skor tinggi nilai $\geq$ dari 5. (B) Faktor Eksternal ibu meliputi (1) Kepercayaan Tradisional di ukur dengan kriteria ibu memiliki/tidak memiliki kepercayaan tradisional. (2) Riwayat antenatal care di ukur dengan kriteria sesuai standar/tidak sesuai standar pemeriksaan ANC dilakukan 4x dengan tenaga kesehatan. (3) Dukungan suami di ukur dengan kriteria kurang mendukung dan mendukung. (4) Akses transportasi di ukur dengan kriteria sulit di akses dan mudah di akses. (5) Ketersediaan biaya di ukur dengan kriteria tidak tersedia dan tersedia. Variabel dependen penolong persalinan yaitu tenaga kesehatan dan non kesehatan. Penelitian ini dilakukan di wilayah kerja Puskesmas Malakopa Kabupaten Kepulauan Mentawai pada bulan Maret 2017.

\section{Kerangka Teori}

Menurut teori Health belief model yang dikembangkan oleh Rosenstock (1950) dalam Noto Admodjo (2007), ${ }^{13}$ kemungkinan individu untuk mengambil tindakan tepat untuk perilaku sehat/sakit dipengaruhi oleh: keyakinan tentang kerentanan individu terhadap keadaan sakit, keyakinan tentang keseriusan atau keganasan penyakit, keyakinan tentang manfaat, dan isyarat atau petunjuk aksi (Cuest). Mengacu pada kerangka teori perilaku health belief model tersebut, maka studi ini mengkaji faktor internal dan eksternal yang mempengaruhi ibu hamil dalam memilih penolong persalinan. Faktor internal yang dikaji adalah pendidikan, status pekerjaan, dan pengetahuan ibu. Faktor eksternal adalah kepercayaan tradisional, riwayat antenatal care, dukungan suami, akses transportasi dan ketersediaan biaya. Latar belakang peneliti memilih variabel sebagaimana tersebut dalam faktor internal dan eksternal karena bisa diukur/dinilai sebagai mana menurut beberapa 
referensi. Menurut Suharsimi Arikunto (1998), variabel penelitian adalah objek penelitian atau apa yang menjadi suatu titik perhatian suatu penelitian. Hal serupa juga disampaikan Sugiyono (2009), variabel adalah segala sesuatu yang berbentuk apa saja yang ditetapkan oleh peneliti untuk dipelajari sehingga diperoleh informasi tentang hal tersebut, kemudian ditarik kesimpulannya. Sedangkan menurut Kerlinger (2006), pengertian variabel adalah konstruk atau sifat yang akan dipelajari yang mempunyai nilai yang bervariasi. Variabel adalah simbol atau lambang yang padanya kita letakkan sembarang nilai atau bilangan. ${ }^{14}$ Selain itu belum pernah dilakukan penelitian di lokus yang dipilih dengan mengkaji jenis variabel ditentukan oleh peneliti. Hubungan variabel dengan pemilihan penolong persalinan adalah setiap variabel memiliki nilai yang berpengaruh signifikan terhadap ibu hamil dalam memilih penolong persalinan baik tenaga kesehatan dan non kesehatan. Tujuan penelitian ini adalah untuk mengetahui faktor yang mempengaruhi ibu hamil memilih pertolongan persalinan di wilayah kerja Puskesmas Malakopa Kabupaten Kepulauan Mentawai.

\section{Hasil}

\section{Faktor yang mempengaruhi ibu hamil memilih} penolong persalinan.

Berdasarkan Tabel 1, persentase terbesar dari gambaran sosio demografi ibu hamil yang bersalin adalah $74,3 \%$ berpendidikan rendah, $80,0 \%$ bekerja, $68,6 \%$ berpengetahuan tinggi, $51,4 \%$ memiliki kepercayaan tradisional, $58,1 \%$ mendapatkan pelayanan antenatal sesuai standar, $65,7 \%$ mendapat dukungan suami, $57,1 \%$ akses transportasi mudah, dan 54,3\% tidak tersedia biaya.

Tabel 1. Gambaran Sosio Demografi Ibu Hamil yang Melahirkan di Wilayah Puskesmas Malakopa Kabupaten Kepulauan Mentawai Tahun 2017.

\begin{tabular}{|c|c|c|c|}
\hline No & Variabel & Frekuensi Determinan & $\%$ \\
\hline & Faktor Internal & & \\
\hline 1 & $\begin{array}{l}\text { Pendidikan } \\
\text { - Rendah } \\
\text { - Tinggi }\end{array}$ & $\begin{array}{c}26 \\
9\end{array}$ & $\begin{array}{l}74,3 \\
25,7\end{array}$ \\
\hline 2 & $\begin{array}{l}\text { Status Pekerjaan } \\
\text { - Tidak Bekerja } \\
\text { - Bekerja }\end{array}$ & $\begin{array}{c}7 \\
28\end{array}$ & $\begin{array}{l}20,0 \\
80,0\end{array}$ \\
\hline 3 & $\begin{array}{l}\text { Pengetahuan } \\
\text { - Rendah } \\
\text { - Tinggi }\end{array}$ & $\begin{array}{l}11 \\
24\end{array}$ & $\begin{array}{l}31,4 \\
68,6\end{array}$ \\
\hline 4 & $\begin{array}{l}\text { Kepercayaan Tradisional } \\
\text { - Tidak Ada } \\
\text { - Ada }\end{array}$ & $\begin{array}{l}17 \\
18\end{array}$ & $\begin{array}{l}48,6 \\
51,4\end{array}$ \\
\hline & Faktor Eksternal & & \\
\hline 5 & $\begin{array}{l}\text { Riwayat Antenatal Care } \\
\text { - Tidak Sesuai } \\
\text { - Sesuai Standar }\end{array}$ & $\begin{array}{l}14 \\
21\end{array}$ & $\begin{array}{l}41,9 \\
58,1\end{array}$ \\
\hline 6 & $\begin{array}{l}\text { Dukungan Suami } \\
\text { - Kurang Mendukung } \\
\text { - Mendukung }\end{array}$ & $\begin{array}{l}12 \\
23\end{array}$ & $\begin{array}{l}34,3 \\
65,7\end{array}$ \\
\hline 7 & $\begin{array}{l}\text { Akses Transfortasi } \\
\text { - Sulit di Akses } \\
\text { - Mudah di Akses }\end{array}$ & $\begin{array}{l}15 \\
20\end{array}$ & $\begin{array}{l}42,6 \\
57,1\end{array}$ \\
\hline 8 & $\begin{array}{l}\text { Ketersediaan Biaya } \\
\text { - Tidak Tersedia } \\
\text { - Tersedia }\end{array}$ & $\begin{array}{l}19 \\
16\end{array}$ & $\begin{array}{l}54,3 \\
45,7\end{array}$ \\
\hline
\end{tabular}


2. Frekuensi ibu hamil memilih penolong persalinan.

Berdasarkan Tabel 2, diketahui ibu hamil yang memilih penolong persalinan dengan tenaga kesehatan sebesar $62,9 \%$ di wilayah kerja Puskesmas Malakopa Kabupaten Kepulauan Mentawai Tahun 2017.

3. Uji Eksak Fisher hubungan antara faktor yang mempengaruhi ibu hamil dan pemilihan penolong persalinan.

Berdasarkan Tabel 3, hasil Uji Eksak Fisher hubungan antara faktor yang mempengaruhi ibu hamil dan pemilihan penolong persalinan di wilayah
Puskesmas Malakopa Kabupaten Kepulauan Mentawai Tahun 2017

Berdasarkan analisis dengan Uji Eksak Fisher pada Tabel 3 terlihat tidak terdapat hubungan bermakna antara kelompok ibu hamil yang di tolong nakes dan non nakes dalam hal tingkat pendidikan, status pekerjaan, pengetahuan ibu, kepercayaan tradisional, riwayat antenatal, dukungan suami, akses transportasi, ketersediaan biaya ( $\mathrm{p}$ value $>$ $0,05)$.

Berdasarkan hasil uji statistik yang diperoleh peneliti mencoba melakukan wawancara mendalam dengan Kader Kesehatan yang bernama KK

Tabel 2. Distribusi frekuensi ibu hamil memilih penolong persalinan di wilayah Puskesmas Malakopa Kabupaten Kepulauan Mentawai Tahun 2017

\begin{tabular}{lcc}
\hline \multicolumn{1}{c}{ Ibu hamil memilih Penolong Persalinan } & Frekuensi & $\mathbf{\%}$ \\
\hline Non Nakes & 13 & 37,1 \\
Tenaga Kesehatan & 22 & 62,9 \\
Jumlah & 35 & 100 \\
\hline
\end{tabular}

Tabel 3. Hasil Uji Eksak Fisher hubungan antara faktor yang mempengaruhi ibu hamil dan pemilihan penolong persalinan di wilayah Puskesmas Malakopa Kabupaten Kepulauan Mentawai Tahun 2017

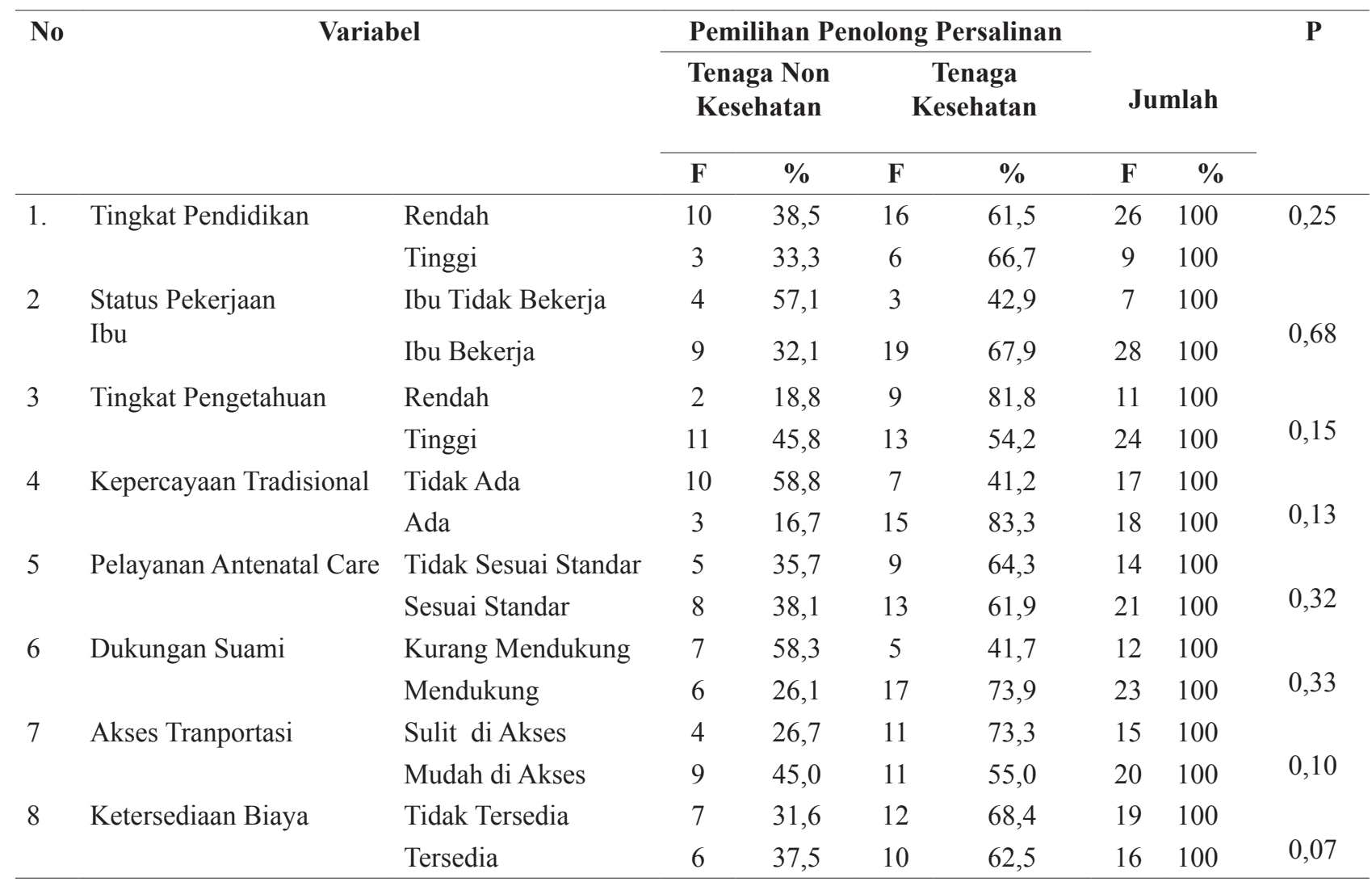


Remaja menyatakan bahwa: kematian ibu banyak terjadi pada ibu hamil yang pendidikan rendah, bahkan ada yang tidak bersekolah, kebanyakan ibu hamil bekerja diladang yang jaraknya jauh di pemukiman penduduk, sewaktu waktu butuh penanganan terlambat di tolong dukun dan bidan akhirnya ibu hamil meninggal. Selain itu ibu hamil tidak memiliki pengetahuan sehingga tidak peduli tanda-tanda bahaya jika ada keluar darah/ lendir dari kemaluannya. Ada juga kepercayaan kita bahwa perempuan hamil harus disembunyikan karena malu jika diketahui orang sehingga kita harus tinggal diladang, ibu hamil yang tinggal diladang ada yang diperiksa kehamilannya ada juga yang tidak, tergantung suaminya kalau suaminya senang istrinya hamil maka akan diajak periksa ke bidan dan sebaliknya ada juga suami yang tidak senang istrinya hamil. Kalau disini masih mudah transportasinya karena dekat ke muara masih bisa cepat ke puskesmasnya, tapi ibu yang tinggal di bagian atas dan pedalaman sangat sulit untuk turun ke muara nya sehingga terlambat pertolongan, dari sisi biaya banyak tidak tersedia karena kebanyakan ibu hamil hanya mengandalkan hasil ladang dan menangkap ikan dan udang di laut. Validitas hasil penelitian dijaga dengan melakukan triangulasi informasi dari informan KK Remaja kepada Kader Terbaik Kesehatan KK.

Hasil konfirmasi membenarkan informasi yang diperoleh dari informan, kalau ada ibu hamil dan bayi mati murni karena terlambat penanganan bahkan semua ibu hamil dimalakopa ini butuh tenaga kesehatan yang selalu standby melayani, karena kami daerah bencana, sejak kejadian gempa dan tsunami kami relokasi keatas sehingga ibu hamil yang hendak pergi berobat/periksa ke puskesmas perlu sarana transportasi seperti motor, mobil ambulan, speed boat jika perlu rujukan.

\section{Pembahasan}

Berdasarkan Tabel 2 proporsi ibu hamil yang memilih penolong persalinan dengan tenaga kesehatan lebih tinggi yaitu $62,9 \%$. Jika dibandingkan dengan data cakupan penolong persalinan oleh tenaga kesehatan di wilayah kerja Dinas Kesehatan Kabupaten Kepulauan Mentawai tahun 2016 sebesar 73,7\% dengan memperhatikan standard pelayanan minimal indikator cakupan penolong persalinan oleh tenaga kesehatan yang memiliki kompetensi kebidanan sebesar 90\%. Hasil penelitian ini menunjukkan masih ada sebesar $37,1 \%$ persalinan ditolong oleh tenaga non kesehatan. Hal ini kemungkinan berkaitan dengan ibu hamil sudah tersugesti dan berkeyakinan dukun bayi lebih berpengalaman, dukun bayi sudah bertahun tahun membantu proses kelahiran warga. Selain itu usia tenaga kesehatan masih muda, dan belum terlalu mengenal baik budaya mereka, belum pernah hamil ataupun merasakan proses melahirkan seperti mereka. Tenaga kesehatan tidak selalu ada ditempat. Penelitian Nolan dalam Paraden Relik Diana (2015), menyatakan wanita hamil akan terpengaruh dengan apa yang dilihat dan didengar dari orang tuanya. Jika orang tuanya melahirkan di rumah maka anaknya juga akan melahirkan di rumah. Pengalaman dari orang tua tersebut, membuat wanita hamil memutuskan memilih melahirkan ditolong oleh dukun. ${ }^{15}$ Menurut hasil penelitian Astuti dalam Nopenanu (2012) persalinan ditolong oleh tenaga non kesehatan sebanyak 90,2\%. ${ }^{16}$ Hasil penelitian yang sama dilakukan Syafrudin dan Hamidah (2009), menyatakan kasus kesehatan yang masih banyak terjadi di Indonesia adalah persalinan yang di tolong oleh dukun. ${ }^{17}$

Belum optimalnya tenaga kesehatan dalam memberikan informasi tentang kesehatan kehamilan dan keamanan dalam melakukan persalinan. Tenaga kesehatan harus merangkul ibu hamil agar terhindar dari risiko bahaya maupun risiko kematian. Hasil penelitian ini didukung oleh temuan penelitian yang dilakukan oleh Ellyana dalam Paraden Relik Diana (2015) diperoleh sebesar (29\%) ibu hamil memilih tenaga non kesehatan sebagai penolong persalinan. ${ }^{15}$ Menurut hasil penelitian Willa Ruben Wadu (2014), menyatakan penyebab kematian ibu hamil adalah perilaku ibu hamil yang memeriksakan kehamilannya ke dukun ${ }^{18}$

Ibu hamil dalam kelompok tingkat pendidikan rendah sebesar $(38,5 \%)$ masih memilih penolong persalinan dengan tenaga non kesehatan. Menurut Notoadmodjo (2007), mengatakan pendidikan secara umum adalah upaya yang direncanakan untuk mempengaruhi orang lain baik individu, kelompok maupun masyarakat sehingga mereka melakukan apa yang diharapkan oleh pelaku pendidikan. Makin tinggi pendidikan seseorang 
makin tinggi pula kesadarannya tentang hak yang dimilikinya. Kondisi ini akan meningkatkan tuntutan terhadap hak untuk memperoleh informasi, hak untuk menolak/menerima pengobatan yang ditawarkan. ${ }^{13}$ Untuk menghindari ibu hamil dari risiko persalinan non nakes maka diharapkan kepada seluruh tenaga kesehatan untuk dapat memberikan informasi yang tepat kepada ibu hamil, agar melakukan persalinan dengan tenaga kesehatan bukan dengan non kesehatan (Dukun). Berdasarkan penelitian yang telah dilakukan oleh Sufiawati (2012) menyatakan variabel yang berhubungan dengan pemilihan tenaga penolong persalinan adalah pendidikan. ${ }^{19}$ Menurut penelitian yang senada dari Nopenanu Yulinda M (2012), menyatakan terdapat hubungan bermakna antara tingkat pendidikan dengan keputusan ibu dalam memilih persalinan di dukun. Ibu yang berpendidikan rendah $(88,9 \%)$ memilih dukun sebagai penolong persalinan, dan ibu yang berpendidikan tinggi $(11,1 \%)$ memilih tenaga medis sebagai penolong persalinan. Pemilihan persalinan dengan dukun lebih banyak, dipengaruhi oleh keputusan keluarga sebanyak $(57,9 \%)$ dan responden yang berpengetahuan kurang sebanyak 14 orang $(87,5) .{ }^{16}$

Menurut Depkes RI (2010), ibu yang memiliki pengetahuan tentang kesehatan reproduksi, akan lebih memiliki rasa percaya diri, wawasan dan kemampuan untuk mengambil keputusan yang baik bagi diri dan keluarganya, termasuk yang berkaitan dengan pemilihan tenaga penolong persalinan. ${ }^{20}$ Hal ini juga didukung oleh penelitian Ninyoman Sasnitiari dkk (2017), menyatakan bahwa kelas ibu hamil adalah sarana untuk belajar tentang kesehatan ibu hamil. Ibu hamil yang mengikuti kelas ibu hamil akan memiliki pengetahuan yang lebih baik dan sikap yang positif dalam mengenali tanda bahaya kehamilan. ${ }^{21}$ Menurut penelitian yang dilakukan oleh Parenden Relik Diana (2015) menyatakan bahwa ibu yang bersalin dengan dukun bayi pengetahuannya kurang dibandingkan dengan ibu yang bersalin di tenaga kesehatan (bidan). Pengetahuan dianggap baik jika seseorang mengambil keputusan yang tepat terkait dengan masalah yang dihadapi, namun mereka yang mempunyai pengetahuan rendah akan mengambil keputusan yang sebaliknya. ${ }^{15}$ Berdasarkan penelitian Mahmudah Ummul dkk
(2011), menyatakan bahwa ibu yang berpengetahuan rendah $(62,5 \%)$ memiliki risiko lebih besar untuk terjadinya kematian perinatal dibanding ibu yang berpengetahuan tinggi $(37,5 \%){ }^{22}$

Tabel 3 proporsi ibu hamil memilih tenaga non kesehatan lebih tinggi pada ibu yang tidak bekerja sebesar $(57,1 \%)$ dibanding ibu bekerja. Menurut Notoatmodjo (2007), pekerjaan juga menggambarkan tingkat sosial ekonomi seseorang, dan hal ini mempengaruhi pemilihan tempat pelayanan kesehatan oleh masyarakat tersebut. ${ }^{13}$ Hasil penelitian ini didukung oleh Rohati 2015 menyatakan bahwa $(44,4 \%)$ responden yang tidak bekerja lebih tinggi memilih penolong persalinan dengan tenaga non kesehatan dibandingkan dengan responden bekerja sebesar (8,5\%). Menurut Harni dalam Rohati (2015), menyatakan bahwa ibu yang bekerja akan menghasilkan uang dan menambah pendapatan keluarganya sehingga mereka leluasa dalam memilih penolong persalinannya. ${ }^{23}$

Berdasarkan hasil penelitian ini, ibu hamil yang memilih penolong persalinan dengan tenaga non kesehatan tingkat pengetahuan rendah sebesar $(18,8 \%)$, dibandingkan dengan ibu hamil yang memiliki tingkat pengetahuan tinggi sebesar $(45,8 \%)$. Ditemukan bahwa ibu hamil dengan tingkat pengetahuan rendah cenderung memilih tenaga kesehatan sebesar $(81,8 \%)$, hal ini kemungkinan mereka telah mendapat penyuluhan dari tenaga kesehatan.

Proporsi ibu hamil yang memilih non nakes tidak meyakini kepercayaan tradisional sebesar $(58,8 \%)$, dan yang menyakini ada kepercayaan tradisional sebesar $(16,7 \%)$. Adanya kepercayaan tradisional masyarakat lokal (Sikerey) bahwa kehamilan itu adalah suatu hal yang tabu. Seorang perempuan yang hamil dalam keluarga tidak boleh diketahui oleh orang lain. Perempuan hamil tersebut harus pergi ke ladang dan harus tinggal mengungsi di ladang yang jauh dari pemukiman warga sampai proses kelahiran bayinya. Meskipun perempuan tersebut sudah menikah atau telah berkeluarga selama kehamilannya perempuan tersebut tidak boleh berhubungan badan dengan suaminya. Perempuan hamil yang melanggar adat tersebut dan diam-diam pulang kerumah biasanya akan didenda. Adanya tradisi lokal ini, menyebabkan tenaga 
kesehatan kesulitan dalam melakukan pemeriksaan kesehatan pada ibu hamil, didukung dengan sulitnya geografis.

Menurut penelitian yang dilakukan oleh Parenden Relik Diana (2015), menyatakan bahwa masyarakat masih memiliki kepercayaan yang tinggi terhadap dukun bayi karena dukun bayi merupakan orang yang berpengalaman dalam hal kehamilan dan persalinan. Masyarakat di daerah terpencil/sulit menganggap bahwa tenaga kesehatan dibutuhkan bila persalinan terjadi komplikasi. Jika persalinan aman maka dukun bayi yang melakukannya. ${ }^{15}$ Penelitian yang dilakukan oleh Handayani dalam Nopenanu (2014), nilai kepercayaan dan pelaksanaan ritual adat istiadat masih kuat dan masih banyak dilakukan oleh masyarakat sehingga peran dukun masih dibutuhkan ${ }^{16}$ Berdasarkan hasil penelitian Kebakyenga dalam Parenden Relik Diana (2015), menyatakan bahwa sebanyak 224 orang $(48,8 \%)$ percaya sama dukun. ${ }^{15}$ Menurut penelitian yang senada dari Nopenanu Yulinda M. (2012), menyatakan bahwa responden yang percaya kepada dukun dan memutuskan memilih persalinan di dukun sebanyak $(72,2 \%){ }^{16}$

Proporsi ibu hamil yang memilih non nakes di kelompok yang memiliki riwayat pelayanan antenatal care tidak sesuai standar sebesar $(35,7, \%)$, dan sesuai standar sebesar (38,1\%). Agar terhindar dari risiko tinggi, komplikasi dan kematian ibu hamil harus mendapatkan pelayanan antenatal care sesuai standar, maka diwajibkan untuk melakukan 3 kali pemeriksaaan yaitu trimester 1, II dan III dengan tenaga kesehatan di fasilitas kesehatan. Ibu hamil yang tidak melakukan pemeriksaan dengan tenaga kesehatan atau bersalin dengan tenaga non kesehatan dianggap tidak sesuai standar. Berdasarkan data Riskesdas 2013 di provinsi Sumatra Barat Kabupaten Kepulauan Mentawai tenaga kesehatan yang memberikan pemeriksaaan ANC pada ibu hamil terbanyak adalah bidan sebesar (86,3\%), dilakukan di Puskesmas/Pustu sebesar $(30,5 \%))^{24}$

Berdasarkan hasil penelitian ibu hamil yang memilih persalinan dengan non tenaga kesehatan lebih tinggi pada ibu hamil yang tidak mendapat dukungan suami sebesar (58,3\%) dibandingkan dengan ibu hamil yang mendapat dukungan dari suami sebesar $(26,1 \%)$, namun hasil penelitian menunjukkan dukungan suami tidak berbeda bermakna dalam memilih penolong persalinan $\mathrm{p}=$ 0,33 .

Proporsi ibu hamil yang memilih persalinan dengan tenaga non kesehatan tinggal di daerah yang memiliki transportasi sulit di akses sebesar (26,7\%) dibandingkan dengan ibu hamil yang tinggal pada daerah yang mudah di akses sebesar (45,0\%). Hasil penelitian menunjukkan akses sulit dan mudah tidak berbeda bermakna dalam memilih penolong persalinan $p=0,10$. Berdasarkan penelitian Handayani dalam Parenden Relik Diana (2015), sarana transportasi menjadi hambatan utama persalinan di fasilitas kesehatan. ${ }^{15}$ Jarak pelayanan kesehatan yang tidak terjangkau mengakibatkan masyarakat memilih untuk mencari pertolongan persalinan yang lebih dekat di karenakan jarak dan waktu tempuh yang jauh memilih persalinan dengan dukun bayi, dan bersalin di rumah disebabkan minimnya sarana transportasi. ${ }^{15}$ Menurut penelitian Kebakyenga dalam Parenden Relik Diana (2015), menyatakan bahwa alasan utama memilih penolong persalinan sebanyak 228 (49,8\%) menjawab karena jarak dari rumah ke fasilitas kesehatan terlalu jauh, dan tidak adanya sarana transportasi sebanyak 164 $(35,8 \%) .{ }^{15}$

Berdasarkan hasil penelitian diketahui bahwa ibu hamil yang memilih persalinan dengan non tenaga kesehatan tidak tersedia biaya sebesar $(31,6 \%)$ lebih rendah dibandingkan dengan ibu hamil yang menyediakan biaya untuk proses persalinannya dengan tenaga non kesehatan sebesar (37,5\%), namun hasil penelitian menunjukkan ketersediaan biaya ibu hamil dalam memilih penolong persalinan tidak berbeda bermakna $p=0,07$.

Hasil ini diperkuat dengan kutipan wawancara mendalam dengan Kader Kesehatan KK Remaja menyatakan bahwa: Sepengetahuan saya tidak ada ibu hamil yang menyiapkan biaya persalinannya saat ditolong bidan/dukun karena ekonomi mereka yang sulit, kebanyakan pendapatan keluarga hanya mengandalkan hasil laut dan alam cukup untuk memenuhi kebutuhan sehari-hari. Kalaupun ada itu mungkin pakai biaya KIS/ Jamkesda untuk persalinannya. Selain itu minjam sama keluarga atau dibantu dari jemaat gereja. Tapi masalahnya tidak semua ibu hamil disini yang menerima KIS/Jamkesda. 
Informasi dari informan KK Remaja diperkuat oleh KK Salome menyatakan bahwa: Kebanyakan Ibu hamil pada saat bersalin dengan dukun dan bidan tidak ada biaya/Jamkesmasnya karena belum mengetahui pentingnya kartu dan manfaatnya buat mereka, meskipun Bapak Presiden Jokowi yang langsung datang membagikan kartu KIS tersebut namun belum semua penduduk yang menerima dan memanfaatkannya.

Menurut Penelitian Sufiawati (2012) mengatakan bahwa ibu hamil yang tidak memiliki biaya mempunyai peluang 1.7 kali lebih besar persalinannya ditolong oleh bukan nakes. ${ }^{14}$ Salah satu kendala penting untuk ibu hamil dalam mengakses persalinan oleh tenaga kesehatan di fasilitas kesehatan adalah keterbatasan dan tidak tersedianya biaya. ${ }^{19}$ Berdasarkan data kepemilikan JKN/Jamkesda belum semua ibu hamil memiliki jaminan kesehatan di Kabupaten Mentawai. Masih tingginya masalah kematian ibu/anak di desa yang ada di Kabupaten Kepulauan Mentawai tidak semuanya diketahui oleh tenaga kesehatan karena tidak semua kasus kematian ibu/anak dilaporkan. Kasus kematian ibu hamil dan bayi karena terlambat penanganan dan infeksi merupakan/ dianggap hal yang biasa saja di masyarakat. Masih kurangnya perhatian pemerintah daerah dalam meminimalisir angka kematian Ibu dan Anak di Kabupaten Kepulauan Mentawai dilihat dari minimnya penyediaan anggaran untuk program, rendahnya kompetensi SDM dalam merealisasikan Dana Jampersal dari DAK non Fisik. Sehingga tenaga kesehatan tidak bisa berbuat banyak dalam memberikan pelayanan kesehatan terhadap program KIA.

\section{Kesimpulan}

Ibu hamil di wilayah Puskesmas Malakopa yang memilih bersalin dengan tenagga kesehatan sebesar $62,9 \%$, masih ada ibu hamil yang melakukan persalinan ditolong oleh tenaga non kesehatan sebesar 37,1\%. Cakupan ini masih rendah dari target SPM (90\%). Gambaran karakteristik ibu bersalin di Puskesmas Malakopa menunjukkan 61,5\% ibu hamil dari kelompok berpendidikan rendah; 67,9\% ibu hamil bekerja; 54,2\% ibu hamil berpengetahuan tinggi; $83,3 \%$ ibu hamil ada memiliki kepercayaan tradisional; $61,9 \%$ Ibu hamil memiliki riwayat pelayanan antenatal sesuai standar; $73,9 \%$ ibu hamil mendapat dukungan suami; 55,0\% akses transportasi ibu hamil mudah; dan 68,4\% dari kelompok ibu hamil yang tidak tersedia biaya. Uji Eksak Fisher menunjukkan tidak terdapat hubungan bermakna antara faktor internal dan eksternal pada kelompok ibu hamil terhadap pemilihan penolong persalinan (nakes dan non nakes), dengan adanya temuan hasil yang perlu dicermati yaitu pada variabel akses dan ketersediaan biaya.

\section{Saran}

Berdasarkan hasil penelitian, untuk menanggulangi risiko biaya persalinan ibu hamil, diharapkan setiap orang sudah memiliki jaminan kesehatan (KIS/Jamkesda) yang diberikan oleh pemerintah. Dinas kesehatan memberikan pendampingan anggaran untuk program KIA, peningkatan kompetensi sumber daya manusia kesehatan khusus yang berdomisili di daerah terpencil. Meningkatkan program kemitraan bidan dengan dukun, menyediakan sarana transportasi yang mudah di akses dengan biaya murah. Melibatkan suami pada saat tenaga kesehatan memberikan penyuluhan, mendampingi istri saat melakukan pemeriksaan kehamilan dan persalinan. Memberikan dukungan biaya selama kehamilan dan proses persalinan, dan memberikan penyuluhan kepada ibu hamil yang memiliki keyakinan tradisional bahwa bersalin dengan tenaga kesehatan jauh lebih aman dibandingkan dengan dukun.

\section{Ucapan Terima Kasih}

Kami mengucapkan terima kasih kepada Kadinkes, Kepala Puskesmas, dan Ibu responden yang telah diwawancarai dan semua pihak terkait yang telah memberikan kesempatan untuk melaksanakan penelitian berkaitan dengan faktor ibu hamil dalam memilih penolong persalinan di Puskesmas Malakopa yang telah memberikan dukungan atas pelaksanaan penelitian dan memberi masukan untuk penulisan ini. Penulis mengucapkan terima kasih kepada Bapak/Ibu yang memberikan bimbingan dan masukan dalam penulisan ini, serta berbagai pihak yang telah membantu pelaksanaan penelitian ini yang tidak dapat penulis sebutkan satu persatu. 


\section{Daftar Rujukan}

1. Media Yulfira, Kualitas Pelayanan Kesehatan Ibu Hamil dan Bersalin di Daerah Terpencil (studi Kasus di Nagari Baatu Bajanjang, Kabupaten Solok, Provinsi Sumbar; 2014; 6(1): 43-52.

2. Badan Litbang Kemenkes RI, 2013. Laporan Nasional Riskesdas tahun 2013.

3. Depkes RI. Pedoman Kemitraan Bidan Dengan Dukun. Jakarta: Depkes; 2008.

4. ht tp://www.koalis iperempuan. or.id/2011/10/19/5-propinsi-penyumbangangka-kematian-ibu-dan-anak-tertinggi/

5. https://www.rumahzakat.org/en/menekanangka-kematian-ibu-dan-bayibrstudi-kasus-diprovinsi-jawa-barat/

6. BPS. SDKI 2012. Jakarta: BKKBN; 2013.

7. Kemenkes RI. Peraturan Menteri Kesehatan tentang Standar Pelayanan Minimal Bidang Kesehatan di Kab/Kota. Jakarta: Kemenkes; 2008.

8. GHPC. Persalinan Sebagai Urusan Desa. Jakarta: GIZ dan Depkes; 2010.

9. www.depkes.go.id.Artikel.13 Februari 2018; p. 1

10. Marisah Rohani, Saswita R. Asuhan Kebidanan pada Masa Persalinan. Jakarta: Salemba Medika; 2011.

11. Dinkes Mentawai, Laporan Profil Dinas Kesehatan Kabupaten Kepulauan Mentawai Tahun 2017.

12. Drs.Imron Moh TA, MM,MBA. Dkk, Metodologi Penelitian Bidang Kesehatan. Sagung Seto; 2010. p.78.

13. Notoatmodjo S. Promosi Kesehatan dan Ilmu Perilaku. Jakarta: Rineka Cipta; 2007.

14. http://www. statistikian.com.

15. Parenden Relik Diana dkk, Artikel Penelitian tentang analisis keputusan ibu memilih penolong persalinan di wilayah Puskesmas Kabila Bone, JIKMU 2015;5 (2a): 1-11.

16. Nopenanu Yulinda M, Faktor-faktor yang mempengaruhi keputusan ibu dalam memilih persalinan di dukun pada wilayah kerja Puskesmas Baumata, MKM; 2014; 08(02): 95107.

17. Sayfruddin dan Hamidah, 2009.Kebidanan Komunitas.ECG:Jakarta.

18. Willa ruben wadu \& Majematang madding, determinan kesehatan ibu dan anak di Kabupaten Manggarai Barat Proviinsi NTT: Buletin Penelitian Sisitem Kesehatan; 2014; 17(3): 249-256.

19. Sufiawati W. Faktor-faktor yang berhubungan dengan pemilihan tenaga penolong persalinan di wilayah kerja Puskesmas Cibadak kabupaten Lebak Provinsi Banten. Jakarta: UI; 2012.

20. Depkes RI. Rencana Stategi Nasional Making Fregnancy Safer (MPS) di Indonesia 20012010. Jakarta: Dirjen Binkesmas Depkes RI; 2001.

21. Ni nyoman sasnitiari, Dwi anggraeni puspitasari, Hubungan keikut sertaan ibu dalam kelas ibu hamil dengan pengetahuan dan sikap terhadap tanda bahaya dalam kehamilan di kota Bogor, Jurnal Kespro, Badan Litbang Kemkes; 2017; 8(2): 175-185.

22. Mahmudah Ummul dkk, Faktor ibu dan bayi yang berhubungan dengan kejadian kematian perinatal. Jurnal Unes Kesmas; 2011; 7(1): 4150.

23. Rohati BR ginting, factor-faktor yang berhubungan dengan pemilihan penolong persalinan ibu di wilayah puskesmas mapaddegat kab.Kep.Mentawai, Univ. Andalas: 2015; p.1-68.

24. Laporan Riskesdas 2013 Provinsi Sumbar, Badan |Litbangkes Kemenkes RI. 